\title{
Do caos do corpo ao íntimo desnudado: a estrutura do deboche no romance $A$ casa dos budas ditosos, de João Ubaldo Ribeiro
}

\author{
Samuel Lima da Silva ${ }^{1}$ \\ Walnice Aparecida Matos Vilalva²
}

\section{Do caos: percepções sobre o romance e o deboche}

O problema era que, quando ele aparecia, tanto Fernando como eu, depois de umas duas cheiradas, estávamos mortos de tesão e de vontade de falar sacanagem e de telefonar para chamar mais gente.

João Ubaldo Ribeiro, A casa dos budas ditosos

De todos os gêneros literários, o romance é certamente o mais escorregadio, o mais difícil de se precisar e de enquadrar em moldes verticais e conclusivos. De sua morte decretada ao ressurgimento, possivelmente atrelado aos estudos culturais, há um arsenal exaustivo de argumentações acerca desse gênero, quase inapreensível em sua configuração temático-estilística. Do amálgama histórico que o envolve, desde o surgimento do romance moderno, com Cervantes, bem como sua evolução, é possível refletir sobre alguns elementos que caracterizam o gênero romanesco e que desembarcaram (não por acaso) em nossa contemporaneidade com maior liberdade que outrora.

Anatol Rosenfeld (1996), em seu conhecido texto acerca do assunto, posiciona o romance moderno pautando-se em três hipóteses fundamentais que o alicerçam: a ideia de um Zeitgeist ${ }^{3}$ sempre presente em todo período histórico; a desrealização no contexto da pintura moderna; e, por fim, o direcionamento destas duas últimas hipóteses, voltando-as para o romance. Nesse processo de analogia entre a pintura do século XX e o romance, o autor afirma

\footnotetext{
${ }^{1}$ Doutorando em estudos literários na Universidade do Estado de Mato Grosso (Unemat), Tangará da Serra, MT, Brasil. Dorcid.org/0000-0003-4135-5513. E-mail: samuellds@live.com

${ }^{2}$ Doutora em teoria e história literária e professora da Universidade do Estado de Mato Grosso (Unemat), Tangará da Serra, MT, Brasil. (Dorcid.org/0000-0002-8507-6527. E-mail: walnicev@ gmail.com

${ }^{3}$ Termo em língua alemã cuja tradução significa espírito da época, espírito do tempo ou sinal dos tempos.
} 
que "a visão de uma realidade mais profunda, mais real, do que a do senso comum é incorporada à forma total da obra" (Rosenfeld, 1996, p. 81). É justamente por meio desse raciocínio de Rosenfeld que nos aproximamos da obra de Ubaldo Ribeiro, pois em seu texto há um rompimento com a realidade do senso comum, mais especificamente em relação ao sexo. É na contemporaneidade que temas e personagens marginais conseguiram, com mais espaço, ter voz e protagonismo na literatura.

No que concerne à definição literária do deboche, esta ainda carece de maior precisão e simetria no âmbito dos estudos literários. Em sua maioria, as pesquisas que se debruçam nas literaturas eróticas apenas retratam superficialmente ou não se aprofundam além da taxação usual com a qual o termo é empregado, cedendo espaço para outras expressões, tais como o obsceno, a vertigem, o grotesco ou o escatológico. Entretanto, seja no campo da filosofia ou no dos estudos literários, o deboche presentifica-se, por excelência, no texto erótico, encontrando neste seu maior ponto de manifestação. Nesse panorama, o deboche acaba por erigir-se, primordialmente, em três polos, a saber: o do inconformismo; o da transgressão; e o da quebra. Por meio desse tripé, ele está alicerçado na literatura contemporânea, diferenciando-se um pouco do deboche escatológico dos libertinos do século XVIII. Na literatura moderna, o deboche aporta como uma lâmina de três lados, convergindo para a mesma direção: a do desejo de liberdade. À vista disso, a referida trinca está presente, por excelência, em $A$ casa dos budas ditosos, conforme veremos posteriormente.

O vocábulo "deboche" deriva do termo em língua francesa debauche, que significa "devassidão", "uma pessoa entregue aos vícios, principalmente da carne". Possui forte ligação com libertino, isto é, o indivíduo que gasta toda sua fortuna em promiscuidade e vícios. No universo literário, o deboche encontra-se manifesto, em especial, na literatura francesa, ${ }^{4}$ mais especificamente nos escritores libertinos do século XVIII, época em que o conceito de libertino não era totalmente negativo, pois estava associado à aristocracia. Entretanto, mesmo que na contemporaneidade o termo seja comumente empregado como

\footnotetext{
${ }^{4}$ Dos escritores libertinos franceses, podemos citar: Restif de La Bretonne, Choderlos de Laclos e, principalmente, o polêmico Marquês de Sade.
} 
sinônimo de cinismo, desfaçatez ou desplante, seu sentido etimológico está na concepção de tripúdio, licenciosidade e depravação. $\mathrm{Na}$ literatura brasileira, por conseguinte, não é sempre que o sexo está atrelado ao universo do deboche.

A obra O caderno rosa de Lori Lamby (1990), da pornógrafa Hilda Hilst, elabora esse elemento tornando-o fundamental para o desenvolvimento da narrativa, haja vista que o deboche se alia a uma espécie de ironia que, aos poucos, assume um caráter bastante evidente de denúncia social. No mesmo segmento, outro exemplo é Pornopopeia (2009), romance escrito por Reinaldo Moraes, no qual o deboche é o elo central de engendramento entre o protagonista Zeca (ex-cineasta de obras marginais) e o mundo que o cerca e o corrói; o deboche, então, figura como expressão de liberdade e, por vezes, até como ato político. Em $A$ casa dos budas ditosos, a narradora utiliza-se do deboche, da ironia e da libertinagem para narrar ao leitor sua história de devassidão. Estritamente, ao final do século XX, Ubaldo Ribeiro entra na categoria de escritores que se utilizaram desse recurso em suas obras. O escritor presentifica uma idosa misteriosa, opaca em sua realidade, mas que consegue, por meio de sua experiência, criticar e, sobretudo, rir da maneira como as mulheres são subjugadas sexual e moralmente.

Essa personagem de Ubaldo Ribeiro é uma dessas vozes que, potencializada pelo escárnio, evidenciam feridas e dilemas sociohistóricos de extrema relevância, conforme veremos no tópico seguinte. Dessa forma, o romance possui mecanismos de composição estético-narratológicos que retomam algumas proposições do romance moderno do início do século XX, como o riso; contudo, conferindo-lhe diferenças no que tange ao processo de narração da protagonista. Michel Butor, em sua análise sobre Joyce e o romance moderno, assevera que: "O que é certo é que nenhuma obra pode ser considerada como verdadeiramente moderna se não levar em consideração, de uma maneira ou de outra, porém, profundamente, alguns grandes fatos, alguns grandes mestres que orientam a paisagem" (1995, p. 13-14). A argumentação do autor nos insere na perspectiva do enfrentamento, ou seja, da obra literária que é feita como embate à outra passada. Na história do romance moderno, sempre houve tanto uma vontade de superar o que já havia sido feito, como um anseio de inovar, de apresentar algo novo. 
Em nossa contemporaneidade, o que ocorre não é necessariamente um embate, mas, sim, um desejo em recriar, narrar de forma diferente aquilo anteriormente que já fora executado. Em A casa dos budas ditosos, por exemplo, o autor se alimenta do caos temporal e espacial criado pelo romance moderno, trazendo a perspectiva do deboche como fio condutor, cuja personagem não se esconde, mas participa efetivamente na condução da narrativa, explorando os vícios da carne, conduzindo o leitor a seu mundo de relações efêmeras e potencialmente carnais. $\mathrm{O}$ caos do corpo se conecta com o íntimo desnudado, elevando o espaço/tempo narrados a um só: o privado.

Nesse entendimento de romance moderno como propulsor de expressões anteriormente relegadas ao expurgo, pensamos o deboche como leitmotiv de diversas narrativas que exploram as mazelas humanas, estando estas associadas ao corpo, à indulgência da malícia e a um possível deslocamento na maneira como esse gênero traduz a experiência vivida e assimilada dos personagens, sobretudo dos protagonistas. Nesse limiar, pensar o romance moderno é refletir sobre uma gama de experiências e vozes que anteriormente eram silenciadas, ou seja, quase uma espécie de grito, em que o ruído principal é o do corpo em colisão com o corpo do outro. Nessa perspectiva, percorremos, partindo desse ponto, a investigação da tessitura desse elemento na configuração geral de $A$ casa dos budas ditosos, de modo a percebermos a forma como o discurso, em primeira pessoa, tonaliza de um vermelho escorregadio a experiência humana voltada ao sexo, e, principalmente, quais as estratégias narrativas que o enredo constrói de maneira a elevar o deboche a artifício fundamental da narrativa.

\section{O inconformismo: de pernas abertas à porta da transgressão}

Tal como mencionado anteriormente, o deboche se estrutura mediante um tripé composto pela inconformação, transgressão, e, por último, pela quebra. Em $A$ casa dos budas ditosos é possível perceber a presença desses três elementos corporificando a construção da narradora-protagonista, bem como de todo o painel erótico traduzido na narrativa. Do início ao fim da trama, suas experiências são fundidas e orquestradas por essa trinca, de modo a tornar o deboche o cerne de todo o processo narratorial, principalmente de sua própria existência. $\mathrm{O}$ 
processo narrativo de A casa dos budas ditosos ocorre de forma tripla, tendo em vista a afirmação do autor de que, à época da incumbência por parte da editora para que escrevesse um romance acerca do tema "luxúria", acabara de receber - de um desconhecido, por intermédio do porteiro do prédio em que trabalhava - os originais do romance, em pequenas fitas de áudio. Coube, então, a Ubaldo Ribeiro a transcrição e autoria da história de uma senhora apenas designada pela sigla CLB, que lhe confiara suas "memórias de libertina".

Dessa forma, o triplo ao qual nos referimos ocorre desde o parágrafo inicial, quando CLB inicia suas memórias e reporta-se a seu leitor/ouvinte - ou seja, o escritor - causando-lhe um efeito de estranhamento, mais especificamente, um deslocamento, pois a trinca se completa com a presença do próprio leitor, de posse do romance já finalizado. CLB dirige-se a seu redator que, por sua vez, assume a figura do leitor. Essa tríade - CLB > escritor > leitor - cria um efeito tridimensional na narrativa, uma espécie de voyeurismo, pois o leitor acaba por se sentir um desconhecido, ouvindo escondido duas pessoas conversarem sobre as mais diversas formas de tripúdio cometidas por um mulher.

A estruturação do deboche, altamente aliada ao discurso erótico, configura-se inicialmente pela inconformação. Todo o processo de construção narratológica da protagonista, suas relações com o outro e com aquilo que a afeta de maneira corrosiva, é proveniente da inconformação da personagem com aquilo que ela considera incorreto, mais precisamente com as contrariedades e falsas aporias que a sociedade empreende sobre o sexo feminino. O inconformismo com o mundo e suas individualidades farsescas acaba por constituir boa parte da libertinagem a que a personagem se submete. Seu inconformismo gera revolta, empoderamento, uma maneira de gritar - ainda que entre quatro paredes - que ela não se sujeita às redomas e platitudes religiosas. A própria ideia de contar sua trajetória de vida advém de uma rebeldia com a palavra escrita, com o verbo:

Decidi fazer este depoimento inicialmente de forma oral, em vez de escrita, pela razão principal de que é impossível escrever sobre sexo, pelo menos em português, sem parecer recém-saído de uma sinuca no baixo meretrício ou então escrever "vulva", "vagina", "gruta do prazer", "sexo túmido" e "penetrou-a bruscamente". Falando, fica mais natural, não sei bem por quê (Ribeiro, 1999, p. 18). 
Inicialmente delimitada pelo inconformismo, a personagem enxerga na oralidade maior liberdade para estabelecer uma argumentação mais clara e objetiva. Não por acaso, é possível perceber uma crítica dirigida a uma camada da erótica literária de baixo valor estético, totalmente voltada à pornografia comercial e em nada substanciosa do ponto de vista estético-literário. Também é perceptível, na passagem supratranscrita, a ironia e o humor que reverberam por todo o romance, provocando um deslocamento no leitor, isto é, o humor em se abordar um tema tabu e, sobretudo, o deboche contraventor da personagem. Enquanto as mulheres são oprimidas, CLB goza.

A postura da narradora, em seu jorro erótico-memorialista, pode ser iluminada pela argumentação de Barthes acerca do desejo. O teórico apresenta, entre outras, a figura do "Mostre-me a quem devo desejar", elucubrando algumas questões sobre o desejo. Nas palavras do autor: "o ser amado é desejado porque um outro ou outros mostraram ao sujeito que ele é desejável: por mais especial que seja, o desejo amoroso é descoberto por indução" (2003, p.128, grifo nosso). No ponto asseverado por Barthes, o que está em voga é o desejo, pouco acima do discurso amoroso e num entrecruzamento com o discurso erótico/pornográfico. Tal desejo é denunciado na carne, na asseveração do corpo, laminado pela interdição da malícia, do assombramento da pele. O outro - ou outros - a que o autor se refere pode ser percebido na figura da idosa CLB narrando suas peripécias sexuais. A protagonista, catalisada pelo inconformismo, rebela-se sexual e moralmente porque, assim como afirma Barthes, ela percebe o quão desejada é, tornando sua heterodoxia um reduto de possibilidades, isto é, liberdade.

A experiência primeira vivida pela narradora ocorreu ainda na préadolescência, com um jovem negrinho, empregado de sua família, que costumava brincar com ela e seu irmão. O sexo entre ambos ocorre logo após CLB tê-lo forçado a se encontrar com ela, às escuras. A recusa do jovem o faz levar um tapa, sempre evidenciado pela narradora com um deboche pré-sexual evidente: "E ainda dei um tapa forte, estalado mesmo, na cara dele. Ele estremeceu e, se preto pode ficar lívido, ficou lívido. Aliás, preto fica lívido, engraçado, você nota os lábios pálidos" (Ribeiro, 1999, p. 27). Essa primeira manifestação do deboche é presentificada no relato posterior de sua primeira experiência sexual.

O deboche deve ser compreendido como uma conduta alheia às normas sociais vigentes, como algo que transgride o paradigma e extrapola os 
muros do interdito, deixando-se entrever na malícia libidinosa dos personagens, e, sobretudo, na quebra, mais especificamente, na ruptura com algo que, por vezes, vem classificado como indizível. É nessa quebra que o véu é retirado e as feridas de uma sociedade falsamente idealizada são reveladas. É dizendo - e praticando - o sexo em vias de desconstrução que o deboche se corporifica. Ainda imatura quanto aos prazeres e condutas sexuais, a protagonista narra de forma humorada sua primeira incursão nesse universo:

A essa altura, ele já estava gostando e se empenhando e me encostei na parede de pernas abertas e puxei muito a cabeça dele, enquanto, me encaixando na boca dele como quem encaixa uma peça de precisão, como quem dá o peito para mamar, com um prazer enormíssimo em fazer tudo isso minuciosamente, eu gozava outra vez. Imediatamente, já possessa e numa ânsia que me fazia fibrilar o corpo todo, resolvi que tinha que montar na cara dele, cavalgar mesmo, cavalgar, cavalgar e aí gozei mais não sei quantas vezes, na boca, no nariz, nos olhos, na língua, na cabeça, gozei nele todo e então desci e chupei ele, engolindo tanto daquela viga tesa quanto podia engolir, depois sentindo o cheiro das virilhas, depois lambendo o saco, depois me enroscando nele e esperando ele gozar na minha boca, embora ninguém antes me tivesse dito como realmente era isso, só que ele não gozou na minha boca, acabou esguichando meu rosto e eu esfreguei tudo em nós dois. É impressionante como eu fiz tudo isso logo da primeira vez, porque foi mesmo a minha primeiríssima vez, e eu nunca tinha visto nada, nem ninguém tinha de fato me ensinado nada, a não ser em conversas doidas com as outras meninas do colégio (Ribeiro, 1999, p. 29).

A perspectiva da primeira relação já enfoca o deleite do corpo; bem contrário a uma focalização que prioriza a virgindade e, com ela, o seu valor moral expresso pela falta de prazer. Não raro, pela própria falta de excitação. O primeiro ato sexual da narradora não demonstra inocência ou algum outro elemento que permita ao leitor perceber qualquer desajuste entre a atitude da personagem e um possível arrependimento da sua parte. Tudo é severamente narrado de maneira a sobrepor o ato ao pensamento. O sexo realizado entre CLB e seu parceiro é o ponto de partida do deboche ubaldiano, no qual o inconformismo da personagem em relação à opressão feminina conduz a uma compensação sexual. Não afirmamos, no entanto, que no respectivo romance a sexualidade é usada como objeto de revolução 
perante alguma circunstância, mas percebemos a conduta libertina da personagem como resquício de liberdade, como empoderamento feminino em uma sociedade que preside o gênero como um constructo único e inabalável da gênese humana. A ascensão social e o poder financeiro tornam-se a forma mais recorrente e, quiçá, o único caminho para se chegar à expressão de "empoderamento" nas representações da mulher no século XIX e início do XX; isto desde Aurélia, passando por Dona Guidinha e chegando em Maria Moura. Nesse percurso, a sexualidade é, com efeito, negligenciada, anulada, como condição para a manutenção do poder. A marca mais indelével do deboche em $A$ casa dos budas ditosos reside no constante embate entre sexo e religião feito pela narradora. CLB parece ainda não se conformar com o modo como os dogmas e as crenças religiosas são impostos na mente dos indivíduos. Durante todo seu relato, CLB ironiza e, munida de um sarcasmo nada velado, critica a alienação religiosa pela qual ela acredita que o universo esteja afetado, conforme é possível ler a seguir:

Com o tempo, ainda nessas férias em que começamos, ele passou a botar nas minhas coxas, e a gente aprendeu a sincronizar o gozo, e eu fazia questão de que ele recuasse um pouco os quadris para gozar nas minhas coxas. Fiquei uma especialista nessa prática, até hoje acho que é muito bom em certas circunstâncias que não sei enumerar, mas sinto quando elas se apresentam. O homem não pode gozar fora, não pode cometer o pecado de Onan, que, como você sabe, não foi se masturbar, mas ejacular no chão, em vez de emprenhar devidamente sua cunhada viúva, se não me engano era a cunhada viúva, ou uma outra parenta em situação semelhante. Está no Velho Testamento, onde, aliás, como eu já disse, estão muitas outras coisas habitualmente denunciadas como reprováveis, que os padres e pastores fingem que não veem (Ribeiro, 1999, p. 35, grifo nosso).

Ao continuar relatando a relação que ocorrera pós-sexo com o seu amigo, a narradora insiste em unir sua vida libertina a um desconsolo em relação à religião. Politeísta e bastante incrédula em relação a diversos pontos que tonalizam a fé humana, a personagem escancara seu deboche libertino perante a fé cristã, causando um deslocamento no leitor, que se vê em face de uma experiência libertária de corpo e espírito. É justamente nesse entremeio (sexo versus religião) que reside o cerne da rebeldia da narradora. Tal sentimento deriva da desolação acerca de uma sociedade que a personagem julga demasiadamente mascarada, principalmente de 
um desconsolo com as pessoas que a cercam. Dessa assolação surge o desejo de transgressão, rigorosamente orquestrado pelo erotismo.

\section{A transgressão e a quebra: do íntimo desnudado, do sexo debochado}

Nada de saudosismo, saudosismo é uma espécie de masturbação sem verdadeiro prazer.

João Ubaldo Ribeiro, A casa dos budas ditosos

Pensar a transgressão é refletir também sobre a maneira como a narradora encara suas experiências sexuais. Bataille afirma que "a transgressão não é a negação do interdito, mas o ultrapassa e o completa" (2003, p. 121), evidenciando que não há interdito que não possa ser transgredido. A argumentação do autor nos ancora na perspectiva de criação literária da narradora de $A$ casa dos budas ditosos, colocando-a em um forte limiar entre a transgressão e o riso, tornando o deboche quase que um resultado dessas duas expressões. $\mathrm{O}$ deboche está fortemente aliado ao riso, ao humor e, por vezes, ao grotesco, sendo que todas essas questões se presentificam na erótica literária, estando conectados entre si. Em Ubaldo Ribeiro, a conexão mais pungente se dá entre o riso e o deboche, isto é, na maneira como a narradora consegue articular a noção de devassidão, descambando para uma comicidade proposital.

Henri Bergson assevera que "o riso tem significado e alcance sociais, de que a comicidade exprime acima de tudo certa inadaptação particular da pessoa à sociedade". A inadaptação a que o autor se refere pode ser compreendida não apenas no inconformismo de CLB em relação à sociedade, mas também com o ciclo de transgressão às normas vigentes, encarando o mundo do modo como ela acredita que deva ser enfrentado, isto é, sem submissão ao masculino. George Minois (2003) argumenta que o riso acaba por ser uma resposta fundamental do homem que vive num constante embate com sua existência. Esse embate existencial entre o homem e a sociedade, primordialmente, a sociedade moderna, acaba por se apresentar no romance moderno confirmando personagens que se exilam emocionalmente, mas que confrontam o mundo à sua maneira. Em Ubaldo Ribeiro, esse enfrentamento encontra-se no corpo, no sexo, na liberdade sexual outrora negada. Em A casa dos budas ditosos, a transgressão não está necessariamente no sexo, mas na forma como este é praticado. 
A vida sexual de CLB e, inclusive, sua atitude de levá-la a público, configura uma necessidade maior de a narradora transgredir os interditos morais da sociedade, conforme a própria protagonista explica: "nesse ponto, sou obrigada a reconhecer meu reacionarismo, embora não radical, é claro. E a hipocrisia da época era mais agressiva, dava muito gosto a quem a desafiava seus mandamentos, acabava resultando num grande prazer, a transgressão era mais satisfatória, melhor para o ego" (Ribeiro, 1999, p. 93). Em todas as suas aventuras sexuais, tanto no Brasil, quanto em Portugal, Estados Unidos, enfim, a narradora afia seu discurso como se quisesse a todo o momento mostrar às mulheres que estas podem se libertar das amarras convencionais do sexo e, principalmente, dialogar de maneira natural sobre ele. No presente, enquanto conta (por meio das fitas) sua história ao escritor, a idosa não aparenta desolação ou tristeza, mas, sim, uma vontade de que suas transgressões sejam levadas ao público, imortalizadas.

É importante ressaltar que o riso e as demais manifestações do humor foram fortes distintivas do romance moderno, desde o seu surgimento, pois, "em paralelo com a história dos fatos, iria se ocupar em representar os conflitos e angústias do homem na modernidade, bem como em refletir acerca dos mesmos" (Barroso e Barroso, 2015, p. 301). Na contemporaneidade, o deboche aporta em Ubaldo Ribeiro como uma espécie de manifestação irônica do que pode ou não estar correto nos padrões morais. Enquanto o simples ato de falar de sexo ainda é tabu, Ubaldo Ribeiro opta por debochar. Tal questão torna-se bastante interessante, parecendo que a perspectiva do riso e do deboche deve ser também questionada. $\mathrm{O}$ riso, uma espécie de licença social para abordar aquilo que avulta, fere. E, nesse sentido, tratar de uma experiência libertina por meio do deboche faz todo sentido. A seriedade assume os riscos na enunciação daquilo que não é autorizado, dos atos escusos.

A ensaísta Eliane Robert Moraes (2015, p. 10) afirma que "assim como o sexo, os números são inequívocas fontes de prazer no mundo do deboche", fazendo-nos enxergar a estruturação da narradora libertina, enquanto jovem, análoga à essa perspectiva, pois a tônica do desejo e do alto número de parceiros com os quais pratica sexo é sempre descrita como fator importante para sua liberdade sexual. Tudo o que é condenável à era moderna, CLB pratica sem pudores. De incesto a orgias, a personagem utiliza o sexo transgressor como arma de ataque, de combate, ora contra seu meio social, ora contra si mesma, num 
constante embate existencial, conforme abordado anteriormente. As atitudes transgressoras de CLB caminham junto à iminência do risco, de uma ousadia que o leitor pode tomar por abuso. O caso, por exemplo, que manteve durante tempos com seu tio Afonso parece demarcar o baixo limite em que a personagem tece suas atitudes e, sobretudo, de como essa violação é sublimada a deboche, pois somente assim entra na zona do dizível. Não poderia ser enunciada de outra maneira.

[...] tio Afonso me sentou no colo e ficou de pau duro, eu ainda devia ter uns doze ou treze anos e o filho da puta ficou de pau duro comigo no colo, mas eu deixei. Não sei o que deu em mim, mas deixei e me mexi bastante em cima do pau dele [...]. Mas eu, que até gostava do perigo de tia Regina nos flagrar, disse que, nesse caso, nunca mais faria nada com ele, ou ele topava ou adeus. Ele então topou e eu ainda lhe dei uma mordida no pescoço para deixar marca e ele ter de inventar uma história qualquer, ele que se lixasse, eu achava que não tinha nada a perder. Tia Regina não me suportava, morreu me odiando, meio caquética, mas ainda lúcida o suficiente para odiar (Ribeiro, 1999, p. 62, grifo nosso).

Nesse ponto, as atitudes da personagem denunciam seu desejo em ultrapassar os muros da proibição, sem limites ou verticalidades. CLB encarna a libertina moderna, mais audaciosa, imperiosa, que torna o risco e a adrenalina ingredientes para o deboche libertário do qual faz uso, não apenas em suas experiências, mas principalmente no ato de rememorá-las, de contá-las ao escritor, tornando-as públicas, eternas. $\mathrm{O}$ jogo estabelecido entre a libertina e Afonso articula-se na perspectiva da caça e do caçador, elevando ambos a um risco de sobrevivência que mais parece ser uma metáfora da vida que viria adiante para a narradora. $\mathrm{O}$ vício em adrenalina, a indulgência, o ódio alheio e os falsos pudores estariam presentes em todo o transgressor percurso de vida da protagonista, inclusive, em sua velhice.

A manipulação estabelecida por parte de CLB ao seu tio prolonga-se por algum tempo, sempre com a personagem torturando-o psicologicamente, em um painel de tons sadomasoquistas. A narradora sente prazer no risco e na aflição causada ao tio, sempre se divertindo com as situações impostas a ele. Das várias torturas que CLB causava, a mais cômica está na recusa de, conforme a própria narradora afirma, "dar-lhe a bunda". Antes do falecimento de Afonso, o grande desejo do parceiro era que sua sobrinha realizasse sexo anal: "sempre quis comer 
minha bunda, e eu nunca dei, mesmo depois que aprendi" (Ribeiro, 1999, p. 64). A odisseia de Afonso em conseguir deflorar, por trás, a sobrinha, é narrada de forma zombeteira e audaciosa. O deboche, plasmado na transgressão do relacionamento incestuoso, é estruturado sob a égide do riso, do humor. Transgredir se presentifica em romper o limite do risco e afetar o outro com a lâmina do desejo não realizado.

Uma vez ele estava em pé e eu chupando o pau dele sentada, sem botar as mãos no pau, como ele gostava - de vez em quando eu fazia as coisas mínimas de que ele gostava, não só porque também não sou nenhuma Torquemada, como porque gostava de mostrar como podia fazer dele gato e sapato - eu estava chupando ele muito aplicadamente mas pensando em artistas de cinema e aí resolvi isso que vou contar. Sem quê nem para quê, disse a ele que ia the dar minha bundinha; mas antes ia chupar mais um bocadinho; e então cantei Einekleine Nachtmusik assim: "Vou, vou vou, eu vou é lhe chupar! Vou, vou-vou, eu vou é lhe chupar!" Allegro vivace: "Vouvou, lhe dar a bunda, vororororô, mas você vai broxar!" Mais ou menos assim, agora não está saindo, mas na hora encaixou tudo certinho, notadamente a intenção, porque, quando ofertei minha bunda e disse que já tinha feito muito bem a minha parte e agora era com ele e acrescentei um "venha logo" petulante, ele obviamente broxou. Visão patética, ele choramingando "mais uma chance, mais uma chance" e eu respondendo "menos uma chance, menos uma chance" (Ribeiro, 1999, p. 74).

A narradora descreve o processo de tortura sexual realizado com seu tio, tornando o espaço da angústia, do delírio, em mero véu para o seu deboche. CLB tem noção do seu poder feminino, usando-o a seu favor e contornando as angústias de seu tio. Sua forma de relatar o ocorrido é, praticamente, seu grande trunfo contra a sociedade machista com a qual sempre lutou. Ela precisa narrar suas experiências elevando o cômico ao nível de transgressão, o deboche como fruto do rompimento com o interdito. Já ciente da possível impotência do tio, a passagem acima é um dos principais trechos no qual o romance estrutura-se tendo como pilar o efeito do deboche. Nessa parte analítica, a argumentação de Bergson (2007, p. 103) é necessária, pois este afirma que “a comicidade não é sempre indício de um defeito, no sentido moral da palavra, e que, se insistirmos em ver nela um defeito, e um leve defeito, será preciso indicar qual o sinal preciso graças ao qual se distingue aqui o leve do grave". O autor aponta para o julgamento moral da comicidade, 
afirmando que o ato de se julgar imoral aquilo que induz ao riso tornase irregular, impróprio, precipitado. Tal afirmação nos conduz, no âmbito dos caminhos da conformação erótica da personagem, à percepção de que a postura de CLB ao enfrentar o mundo misógino, apesar de implicar num muro de ordem moral, faz com que o leitor, no presente, ao ler suas memórias, veja sua experiência não como libertadora, mas como opressora. É nessa dualidade entre a liberdade e a opressão que a quebra, último elemento da trinca, manifesta-se.

Na perspectiva do romance moderno, da qual a narrativa de Ubaldo Ribeiro retoma algumas proposições, tais como o riso elevado ao deboche e a baixa temporalidade, isto é, o presente de CLB essencialmente ligado a seu passado (sendo este o ponto de partida para que suas memórias narrativo-eróticas se concretizem), a percepção da quebra como elemento funcional-regulador da diegese ubaldiana é de fundamental apoio para a argúcia do painel erótico que a trama desvela. Desse modo, a quebra que completa o deboche em $A$ casa dos budas ditosos presentifica-se no presente, com CLB utilizando sua trajetória de vida como instrumento de libertação, de maneira que outras mulheres não se subjuguem mais ao universo masculino: o empoderamento feminino advém por meio da liberdade sexual da narradora autodiegética. A quebra é, portanto, um operador produtivo no romance, rompendo com a barreira do particular, desnudando o íntimo ao público. A narradora esboça o desejo de que suas memórias sejam publicadas antes de sua morte:

No começo, achei que ia deixar estas delusões - como dizia meu professor de Medicina Legal - para serem publicadas depois de minha morte. Mas num instante vi que era burrice, nada vale a pena depois da morte, eu quero é passar na rua e ver as caras das pessoas que leram, todo mundo fingindo que não é nada com eles. Nada desse negócio pequeno-burguês de depois da morte. Antes da morte, tudo antes da morte, é ou não é? E, por outro lado, me arriscaria a eles darem um jeito de destruir os originais, não me pergunte como, eles são diabólicos (Ribeiro, 1999, p. 18).

A quebra pode ser mais bem percebida quando utilizamos o espelho como metáfora. Percebamos, portanto, a quebra como um espelho, nele refletindo as experiências vividas e assimiladas da idosa; percebamos, ainda, refletida nesse espelho, a imagem do leitor. Temos, então, um espelho que imagetiza o tripúdio da narradora, focando o elemento social 
como alvo. Após essa percepção, imaginemos sua quebra em centenas de cacos, todos espalhados pelo chão, laminando os passos de quem passa por cima sem, no entanto, deixar ainda de refletir as experiências da narradora. Experiências estas eternizadas no livro de suas memórias, do romance que incumbira o escritor de escrevê-lo. A corporificação da quebra enquanto elemento funcional na narrativa advém, principalmente, quando o deboche defronta-se com o estatuto do sério, mais especificamente, como aquilo é ou não percebido como dizível. Todas as memórias da personagem enquanto jovem apenas são possíveis de serem narradas e publicadas porque estão sob o véu do riso, da ironia, de uma maneira em se dizer o não dizível de uma forma passível de ser dita. Enquanto representação de uma mulher presente em uma sociedade heteronormativa, CLB só consegue levar sua trajetória libertina ao público quando se desarma da "seriedade", cedendo espaço ao cômico, mais precisamente, ao deboche. O desejo de publicar suas memórias - ou seja, o anseio para que sua existência atinja o sexo feminino de forma que este reaja contra a hipocrisia social - torna o romance de Ubaldo Ribeiro um estilete apontado para a face da sociedade, ferindo abertamente a pele misógina que recobre a existência humana.

O discurso social que existe em A casa dos budas ditosos é caracterizado inicialmente pela figura da libertina, da pervertida, daquela que vive na marginalidade do desejo, no obscuro da carne, sendo pela via do discurso erótico-debochado que a experiência de CLB é posta em cena. O ciclo estruturante do deboche se completa perfazendo uma narrativa que faz uso do sexo como expressão pungente de liberdade, de grito social ainda preso em nossa contemporaneidade. Partindo de seu inconformismo, perpassando pela transgressão, a ruptura feita pela narradora ao jorrar suas memórias ao público confirma a hipótese de que o deboche, nesse romance, além de se estruturar como pilar para a luta contra a opressão feminina, também instaura um humor e ironia que, senão deliciosos, de certa forma fazem o leitor encarar sua própria conduta como a idosa libertina afirma: "Eu não pequei contra a luxúria. Quem peca é aquele que não faz o que foi criado para fazer" (Ribeiro, 1999, p. 76).

\section{Considerações finais}

Com base no percurso analítico empreendido, percebemos o deboche como elemento fundamental na estruturação do romance de João 
Ubaldo Ribeiro. Por meio de uma narradora autodiegética, o sexo e o riso são elevados ao nível do deboche, sendo este edificado por uma via de mão tripla: o inconformismo, a transgressão e a quebra. Por meio deste tripé, o romance se desenvolve conjecturando as atitudes da narradora libertina, em sua juventude, a um desejo de liberdade, fazendo do riso e do humor, expressões para que a tessitura do deboche se perfaça. Publicado ao final do século XX, A casa dos budas ditosos retoma marcas de uma das principais características do romance moderno, o riso; no entanto, dando nova configuração a este elemento, fundindo-o com as experiências sexuais da protagonista, mesclando um passado longínquo a um presente disforme e presentificando o sexo como crítica e, principalmente, como denúncia.

\section{Referências}

BARROSO, Wilton; BARROSO, Maria Veralice (2015). Entre o passado e o presente do romance moderno: o humor na escrita de Milan Kundera. Letras \& Letras, Uberlândia, v. 31, n. 1, p. 290-311. Disponível em: <https://goo.gl/DrhSrw> Acesso em: 2 fev. 2017.

BARTHES, Roland (2003). Fragmentos de um discurso amoroso. Tradução de Marcia Valeria Martinez de Aguiar. São Paulo: Martins Fontes.

BATAILLE, Georges (2013). O erotismo. Tradução de Fernando Scheibe. Belo Horizonte: Autêntica.

BERGSON, Henri (2007). O riso: ensaio sobre a significação da comicidade. Tradução de Ivone Castilho Benedetti. São Paulo: Martins Fontes.

BUTOR, Michel (1969). Joyce e o romance moderno. In: BUTOR, Michel; SVEVO, Italo; ECO, Umberto. Joyce e o romance moderno. São Paulo: Documentos.

HILST, Hilda (2014). Pornô chic. São Paulo: Globo.

MINOIS, George (2003). História do riso e do escárnio. São Paulo: Editora da Unesp.

MORAES, Eliane Robert (2015). O inventário do abismo. Prefácio. In: SADE, Marquês de. Os 120 dias de Sodoma ou A escola da libertinagem. 5. ed. Tradução de Alain François. São Paulo: Iluminuras.

MORAES, Reinaldo (2009). Pornopopéia. Rio de Janeiro: Objetiva.

RIBEIRO, João Ubaldo (1999). A casa dos budas ditosos. Rio de Janeiro: Objetiva. 
ROSENFELD, Anatol (1996). Reflexões sobre o romance moderno. In: ROSENFELD, Anatol. Texto/contexto. São Paulo: Perspectiva.

Recebido em 29 de abril de 2017.

Aprovado em 18 de outubro de 2017.

\section{resumo/abstract/resumen}

\section{Do caos do corpo ao íntimo desnudado: a estrutura do deboche no romance $A$ casa dos budas ditosos, de João Ubaldo Ribeiro}

Samuel Lima da Silva

Walnice Aparecida Matos Vilalva

O romance $A$ casa dos budas ditosos (1999), de João Ubaldo Ribeiro, utiliza-se do deboche para construir toda a plataforma narrativa presentificada pela voz de uma narradora-protagonista idosa, beirando os 70 anos, identificada apenas pela sigla CLB. A trama gira em torno dessa baiana, residente no Rio de Janeiro, que decide narrar boa parte de sua vida enfatizando a luxúria, o sexo, as redomas sociais e, sobretudo, a independência do corpo. Nesse limiar, apontamos a expressão do deboche como pedra de toque para demonstrar a narrativa de Ubaldo Ribeiro como articuladora das noções de ironia, riso, vício e devassidão, engendradas pelo sexo, evidenciando o tripúdio como uma das expressões do romance moderno.

Palavras-chave: João Ubaldo Ribeiro, A casa dos budas ditosos, romance moderno, deboche.

\section{From body chaos to intimacy exposed: the structure of debauchery in the novel $\boldsymbol{A}$ casa dos budas ditosos by João Ubaldo Ribeiro}

Samuel Lima da Silva

Walnice Aparecida Matos Vilalva

The novel A casa dos budas ditosos (1999), by João Ubaldo Ribeiro, uses mockery as its narrative thread. The narrative is represented by the voice of the narratorprotagonist - an elderly woman of about 70 years who only identifies herself through the initials CLB. This woman from Bahia, who now lives in Rio de Janeiro, is at the center of the plot. She decides to tell most of her life story highlighting lust, sex, social barriers and prejudices, and, above all, sexual independence. We underscore mockery as the narrative's cornerstone to show how Ubualdo Ribeiro's novel articulates the notions of irony, laughter, 
addiction and debauchery that are generated by sex. The article thus proposes mockery as one of the elements of modern novels.

Keywords: João Ubaldo Ribeiro, A casa dos budas ditosos, modern novel, mockery.

\section{Del caos del cuerpo al íntimo desnudado: la estructura del escarnio en la novela A casa dos Budas Ditosos, de João Ubaldo Ribeiro}

Samuel Lima da Silva

Walnice Aparecida Matos Vilalva

La novela A casa dos budas ditosos (1999), escrita por João Ubaldo Ribeiro, utiliza el libertinaje para construir toda la plataforma narrativa personificada por la voz de una narradora-protagonista anciana, rayando los setenta años de edad, identificada apenas por la sigla CLB. La trama gira en torno de esa bahiana, residente en Rio de Janeiro, que decide narrar gran parte de su vida enfatizando la lujuria, el sexo, las burbujas de cristal sociales, y, sobre todo, la independencia del cuerpo. En ese aspecto, apuntamos para la expresión del libertinaje como piedra angular para presentar a la narrativa de Ubaldo Ribeiro como articuladora de las nociones de ironía, vicio y libertinaje, tocantes al sexo, evidenciando la impudicia como una de las expresiones de la novela moderna.

Palabras clave: João Ubaldo Ribeiro, A casa dos budas ditosos, novela moderna, libertinaje, impudicia.

\section{Nota:}

Samuel Lima da Silva é bolsista da Coordenação de Aperfeiçoamento de Pessoal de Nível Superior (Capes). 